\title{
Urbanization and the Development of Gender in the Arabic Dialects
}

\author{
Muhammad al-Sharkawi \\ Wayne State University, Michigan, USA
}

\begin{abstract}
This article makes the claim that the difference between typologically Bedouin and urban dialects of Arabic in gender representation in the plural, is a function of the urbanization process the urban dialects of Arabic went through in the seventh century in the conquered territories. Contact induced linguistic processes of koineization and structural simplification in the newly established urban centers in the Middle East and North Africa immediately after the Arab conquests helped enhance the gender development that was already in effect before the Arab conquests. By comparing Bedouin and urban dialects to Classical Arabic, the article establishes that the three varieties were in a process of development in gender. Classical Arabic stopped at a particular stage, and Bedouin and urban dialects continued. Comparing Central Asian dialects to urban dialects of Egypt, they can see that at least to the eighth century, gender was a common feature of peninsular dialects. The article concludes by stating that the urban dialects developed further to lose all gender distinction in the plural because of the leveling and borrowing processes of the koineization in the urban centers in their formative period.
\end{abstract}

Keywords: urbanization, gender development, Arabic dialects

\section{Introduction}

In the last 25 years, since Thomason and Kaufman's (1988) seminal work on contact-induced language changing the relationship between structural development and human contact took center stage in the field of language development. Although the relationship between the non-linguistic settings (urban and/or otherwise) and the formal aspects of language became prominent in socio-linguistics as early as the 1960s, the relationship between the urban setting and change in language behavior and development did not take momentum much further beyond the theoretical establishment, at least in the field of Arabic linguistics. Research in this relationship started to take a serious and continuous shape in 2004 by a roundtable on the urban setting and its impact on linguistic behavior in Aix en Provence. The proceedings of this roundtable were later published in a book to make the first book length attention to the subject after Versteegh's initial attempt in 1984 and Owens's edited volume in 2000. However, the relationship between urbanization and the historical development of Arabic has only been touched upon before al-Sharkawi (2013) made the claim that the urbanization process in the Middle East and North Africa in the seventh century, led to the emergence and learning of New Arabic vernacular type in these areas.

\footnotetext{
Muhammad al-Sharkawi, Wayne State University.

Correspondence should be addressed to 1175 Pond Ridge Drive North, Troy, MI 48085, USA. Email: mohamed.el-sharkawi@wayne.edu.
} 
The current article builds upon this general argument. The jest of al-Sharkawi's (2010) thesis is that when Arabs migrated to certain designated areas, they gathered from several tribes in the garrison towns. Although demographically the migrants belonged to various tribes, waves of migration were characterized by their small size and stability of source tribes. Through contact processes of leveling and regularization took place, rendering different koines in different garrison towns because the tribes that participated in the population of each garrison differed. After the conquests proved lucrative, the financial benefits of living in the garrison towns became obvious, and the commercial and agricultural conditions in the provinces worsened, sectors of the monolingual local populations migrated to the vicinity of the booming garrison towns. Due to an imbalance of prestige and wealth, the language of the job givers and wealth owners, Arabic, was chosen to be the language of communication between both groups. Because learning Arabic was informal and the desire to communicate was mutual, Arabs used simplification strategies to make their language more accessible to non-Arab learners. Structural differences between the old peninsular dialects and those of the New Arabic type of the language that was used in the garrison towns, therefore, can be ascribed to the effect of these two contact strategies, koineization and simplification.

However, al-Sharkawi (2010) did not discuss the direct influence of urbanization and its contact induced strategies on the structural features of the peninsular dialects. In this article, he will undertake this task and try to establish one of these areas of influence. He will look into the relationship between urbanization and the differential development of gender in the dialects of Arabic, after the Arab conquests of the Middle East and North Africa in the seventh century CE. The article makes the claim that the difference between Bedouin dialects of Najd, Eastern Arabia, and their descendants and the urban dialects of Egypt, Syria, Iraq, North Africa and of course the Hijaz region in gender behavior, is a function of the urbanization process that the latter group of dialects went through in the second half of the seventh century CE.

There is a group of modern dialects of Arabic that have a morphological gender distinction on plural nouns between masculine and feminine, on the second and third persons plural, on verbs of all tenses and on other morphological word classes. These dialects also have a complex plural feminine agreement. These will typologically be called Bedouin dialects. Other dialects do not have a morphological distinction between plural feminine and plural masculine nouns, verbs and/or any other word classes. These dialects also lack a syntactic plural feminine agreement. These dialects are called here urban dialects. The loss of feminine plural syntactic agreement in the urban type of dialects takes these urban varieties from the category of languages that have a syntactic gender distinction more towards the category of the languages that have word classes and not a gender, (Corbett, 2007, p. 241-279) although the process is not complete, as they will see in this article. To the first Bedouin group of dialects belong to most of the peninsular Bedouin dialects, some Sinai dialects, and the Arabic language islands in Central Asia. The second urban group of dialects is that to which the urban dialects of the Middle East and North Africa belong. Of special interest here are the Egyptian, the Iraqi, and Syrian dialect groups.

\section{Urbanization and the Development of Urban Arabic}

The early urbanization process, as they claim here, indirectly caused the structural variation in representing gender between the two types of dialects on the morphological and syntactic levels, in the first century of the Arab conquests of the Middle East and North Africa. Modern scholarship on urban sociolinguistics, Arabic dialect description, and the history of Arabic allows them to draw a possible link 
between non-linguistic ecological causative factors and linguistic effects. Their understanding is that the conquest of Egypt, Syria, Iraq and North Africa ushered in a process of urbanization. The habit of the establishment of Garrison towns from the seventh century $\mathrm{CE}$ onwards brought together to the new provinces group of speaker of similar but not identical dialects of Arabic for a long period of time in close contact in these garrison towns, then brought groups of non-Arabic speaking locals to the vicinities of garrison towns, and contact caused leveling, structural simplification and an informal process of learning Arabic to take place in order for communication to happen between the two language groups (al-Sharkawi, 2013, p. 60-70).

Imperial Arab policies of migration prevented Arabs from living outside the garrisons at least in the first half of the first century of conquest. Economic wealth from revenues of the conquests was concentrated within these garrison towns and attracted fresh Arab migrants from the same conquering tribes. Local non-Arabic speakers lived in rural or semi-rural communities and relied on agriculture for livelihood (Bagnal, 1993). But due to over-taxation, the cut in trade routes after the conquests, and the failure to maintain irrigation systems, agriculture collapsed towards the end of the first century of conquests. Groups of monolinguals migrated to the vicinities of the wealthy Arab garrison towns. This demographic ecology triggered off two contact-induced language processes: koineization and structural simplification. Al-Sharkawi (2013) suggests that the concentration of Arabs in the garrison towns, the migration of small numbers from the same tribes all the time, and the lack of further migration allowed the speakers of peninsular dialects to stay in stable contact for a long period of time. Processes of leveling and borrowing established a distinct koine in each garrison town.(p.61)

When locals started to migrate to the vicinities of garrison towns, at the end of the first century, they must have found that the structural variations among the dialects in the garrison were leveled out, the adjustments completed and the koine fairly established. That koine must have been the learnable input in the process of learning. Arabic informally these local migrants had to go through. Because there was no organized endeavor of teaching and learning Arabic at this early stage, and the learning process depended largely on the native speaker's informal output. Socio-political and demographic ecological factors determined that the Arabic language be used as the language of communication between the two monolingual groups. In cases where pidginization is not possible. Two aspects of the Foreigner Talk registers are relevant to their purpose: regularization and structural simplification. The complete loss of the case system, which existed in the dialects of some Arab tribes before the conquests, and feminine plurals can be ascribed to the regularization process. Pre-Islamic dialects that did not go through this process of urbanization must have kept the feminine gender and the feminine marker on the plural nouns, pronouns, demonstratives and verbs.

In comparison to pre-Islamic dialects, Classical/Modern Standard Arabic relative structural complexity, structural simplification on all levels of linguistic analysis in the modern dialects of Arabic can be considered an indicator of the effect these two contact-induced strategies had on the peninsular dialects of Arabic during the period under study in this article. Functionally speaking, from the point of view of a language user (foreigner and native speaker alike), complexity and of course simplification are the amount of effort a person has to exert to get a working knowledge of the target language (Kusters, 2003, p. 6). For a non-native speaker of Arabic the task of learning the language was much easier because the effort exerted in the learning process must have been less daunting after the leveling and regularization from koineization and the development of structural saliency from the Foreigner Talk registers that must have been used by Arabs. Since the input that came into the learning process was already regularized and salient, the language informally acquired must exhibit structural simplification on all levels of linguistic analysis. The comparison between the modern 
dialects of Arabic and Classical Arabic (the nearest variety to Old Arabic dialects of the Peninsula) shows the influence of simplification on all levels of linguistic analysis in the dialects.

It has been suggested that simplification, according to Kusters, can be analyzed into general linguistic principles (Kusters, 2003, p. 6). Two of these universal linguistic principles are particularly relevant to their purpose here: economy and transparency. The economy principle states that as few the semantic categories as few as possible are expressed by one morpheme. Economy, therefore, correlates with the reduction of the number of categories in the inflectional morphology of the language. The fewer categories the simpler the morphological system becomes. In Ki-Nubi, an Arabic-based Creole in East Africa, the two categories of aspect and voice are the only semantic categories represented by this variety's verbal morphology. Ki-Nubi is structurally simpler than Moroccan Arabic, which represents morphologically the categories of aspect, voice, and agreement with person, gender and number (Kusters, 2003, p. 22). The transparency principle states that the relationship between form and meaning should be as transparent as possible. It means that a separate form expresses one meaning. The exponents of the semantic category must have a defined form and position in the morphological structure of the word (Kusters, 2003, p. 26).

Taking Classical Arabic as a point of reference, they can see that it is not very economical in its verbal inflectional morphology. It has a complicated mood system for verbs, it distinguishes between persons in perfective and imperfective, it is elaborate in number and gender expression by means of suffixes on perfective and imperfective verbs (Kusters, 2003, p. 121). In addition, the category of noun carries number, gender, and case morphemes. As far as transparency is concerned, Classical Arabic does not express the lexical meaning of the root independently from the augmentation patterns. In addition, the meaning of the augmented patterns is not always clear or in one-to-one correspondence with the form of augmentation. Furthermore the expression of several other semantic categories depends on forms and other categories. Aspect expression depends on the lexical root. If the lexical root makes a weak verb, its vowel behavior is different from strong verbs when aspect is projected on the verb. The suffix of person, gender, and number depends on the lexical root (if the root is weak) and on the aspect of the verb. Mood affixes also depend in part on the weakness of the root consonants and on the shape of the person, gender, and number suffixes (Kusters, 2003, p. 122).

The Bedouin Arabic dialects did not emerge from a process of urbanization rank lower in the economy principle than Classical Arabic, but they also rank higher than the dialects that emerged through a process of urbanization. The dialects of Najd are old peninsular dialects that existed from pre-Islamic times and did not go through the leveling and regularization of koineization or the saliency of "foreigner talk". The augmentation system remains in close proximity to the system in Classical Arabic, and the syntactic categories of passive voice and verbal aspects are also the same as in Classical Arabic (Kusters, 2003, p. 131). From the formal morphological point of view, in nouns, three numbers and two genders are expressed by means of affixation on almost all word classes. Unlike Classical Arabic, though, the Najdi dialects lost the dual number on verbs as did the rest of the peninsular and non-peninsular dialects. In addition, the category of mood is totally lost from verbs. In general, the morphological principles operative in Classical Arabic are still operative in Najdi Arabic (Kusters, 2003, p. 134).

Now, if they move to the dialects of Arabic that they claim came into being in a context of urbanization and were developed by means of a leveled input that was made salient during the acquisition process, they will see structural differences from both Classical Arabic and the Najdi dialects. The modern dialects of Arabic are morphologically simpler than Classical Arabic (Holes, 2004, p. 317). There is, they will notice, a higher level 
of economy and transparency in the different morphological verbal paradigms. They know for example that in the modern dialects, the augmentation system shrank to a great extent and went through a process of restructuring (Holes, 2004, p. 125). In Classical Arabic, the augmented forms show some redundancy in the semantic categories they express such as passive, transitive, causative and reflexive. The dialects removed some of this redundancy and reduced the range of meanings associated with each augmented form (Holes, 2004, p. 135). While Classical Arabic has 10 frequent augmented forms and five less frequent ones, the dialects of Morocco, for instance, have six forms only in use (Kusters, 2003, p. 136).

In terms of the category of number, the dual number is lost in the second and third persons of imperfective and perfective verbs. As far as the gender of the verb is concerned, the category is reduced in the urban dialects. In addition to the loss of the gender distinction in the first person plural in Classical Arabic and Najdi Arabic, urban dialects lost gender distinction in the second and third persons plural in both the perfective and imperfective alike. Add this to the loss of the dual number category on all persons and you see that gender is limited to the singular in the three persons (Holes, 2004, p. 119; Kusters, 2003, p. 138-139). Verb conjugations were reduced from 12 or 13 in Classical Arabic to eight in the urban dialects in general and seven in Tunisian Arabic in particular. Besides the loss of the dual number category and the partial loss of the feminine gender category, the dialects also lost the category of mood from the imperfective verb. It was replaced by a set of prefixes (Kusters, 2003, p. 139). All the modern urban dialects also lost the category of voice (Kusters, 2003, p. 138). There was, in addition, a loss of the category of internal passive in the urban dialects (Holes, 2004, p. 122). In Classical Arabic voice it can be expressed internally by means of changing the vowel structure of the verb and by using some augmented forms such as V, VII and VIII. In the urban dialects, an augmented form is the only means of expressing the passive voice.

\section{Gender in Arabic}

The discrepancy between gender behavior in Classical Arabic, Bedouin dialects and Urban Dialects are the different effects in economy and transparency. In the dialects, it must have been the result of the simplification and regularization processes the Arabic language came across during Urbanization in the seventh century. In general, Arabic has no neutral gender. It has two grammatical genders that are traditionally called masculine and feminine. Masculine both in Classical Arabic and in all kinds of dialects is not marked, but feminine nouns may or may not be marked. Animate and inanimate nouns have grammatical gender even if they are not marked. Gender is marked in Classical Arabic and in some of the dialects only in verbs, demonstratives, and pronouns. In Classical Arabic only the category of the relative pronouns is marked for gender as well as number. In Classical Arabic and some dialects, there is plural feminine agreement, and in other dialects the masculine plural serves as a common gender agreement (Hachimi, 2007, p. 155-164). From a comparative point of view, Arabic expresses gender in three degrees. First is the Classical Arabic and its Modern Standard Arabic off spring. Gender is represented morphologically and syntactically. Morphologically, gender is represented on all word classes, except on the first and second persons singular of verbs and pronouns. Syntactically, although concord is complicated and relies on animacy, discourse, and style, there is a complete gender agreement on the clause and sentence levels. Second, there is a Bedouin group of dialects that have a gender system that is somewhat similar to the one used in Classical Arabic. In these dialects, gender is represented on all noun categories in the plural. Although all the dialects have lost the dual paradigm except in nouns, feminine gender is represented on singular and plural nouns, all verbs, pronouns, and in some dialects, 
the demonstrative pronouns paradigm. Unlike Classical Arabic, this group of dialects has lost the relative pronoun as a gendered paradigm. Syntactically, there is complete gender concord on the clause and sentence levels in these dialects. Third, there is an urban group of dialects that projects gender on in singular nouns, singular second and third person verbs, on pronouns and on demonstratives. This group of dialects shows no gender distinction on the plural. Syntactically, this third group does not have a feminine plural agreement on the clause and sentence levels.

He will describe the gender system in Egyptian Arabic, a group of dialects that have presumably been the product of an urbanization process. He will compare the gender behavior of this dialect group to one of the dialects that have not come across a similar process of urbanization, namely the Najdi dialect group. The dialect now spoken in Egypt is the product of a rigorous urbanization process, which triggered off contact situations where particular registers were used (Foreigner Talk registers and nonnative speaker interlanguage), and finally led to the use of these contact induced registers as the main source of learnable input in Arabic. The urban context of garrison towns was the catalyst in which different groups of Arabs came in contact with one another and with largely homogeneous monolingual groups of Coptic speaking local population. Najdi Arabic dialects are spoken in an area in which no garrison town similar to the ones built in Iraq, Egypt and North Africa were established, no diverse dialect speakers came in contact for a sustained period of time and no large groups of a foreign language speakers came in contact with Arabic speakers and no contact induced input providing registers were used. In short, there was no large-scale process of learning Arabic informally which was taking place. Contact from urbanization is supposed in this article to have participated in forming the differential development of the sedentary dialects of Arabic (Egyptian Arabic) and non-sedentary dialects (Najdi Arabic being one example). References to other dialects that belong to each of the two groups will be made when it is necessary to show a trend of development.

\section{Urbanization}

They have adopted a customized definition of urbanization to suit their purpose in this article. Urbanization as a social process is defined in this article as the establishment of ethnically, culturally, linguistically, or socially diverse non-agricultural communities. The establishment and maintenance of Arab garrison towns in the provinces, the migration of Arabs from different tribal, social and dialectal backgrounds to these garrisons, and their engagement in activities other than agriculture are all urban activities. Migration is essential to both the physical act of urbanization and the contact-induced development of the Arabic varieties in the previously mentioned provinces. Although urbanization in Iraq, Syria and Egypt is a diverse and complicated process, the discussion here is limited to the aspects of the phenomenon that are directly relevant to the initiation of contact-induced language processes. A discussion of the whole urban phenomenon is beyond the scope of this article. It, therefore, will elaborate only on the elements pertaining to the linguistic development of the Arabic language directly.

Because the main focus of this article is the development of linguistic structures of the Arabic language in the conquered territories, some aspects of the urbanization process, important to the establishment of Arabs in the provinces as they were, are overlooked in this working definition. For instance, aspects of internal local population numbers and social structure may be important in discussing how the local populations learned and acquired the Arabic language. Similarly, aspects related to the agricultural activities in the immediate desert circles surrounding the garrison towns can also be relevant to other contact-induced processes such as 
pidginization. In addition, Arab outposts in the hinterlands can be relevant to other contact-induced processes such as borrowing. However, the relevance of these factors to the specific contact-induced native speaker initiated language innovation is not relevant.

Socio-linguists have considered urbanization, for the last two decades at least, as one of the most important catalysis for social and linguistic change in human history. Urbanization is especially relevant to the case of the Arabic language development and its historical structural development. As a result, urban socio-linguistics became an important branch of language development and variation studies on both the theoretical and analytical levels. However, the relationship between urbanization as a catalyst for social change and structural innovation and change was not thoroughly studied in its historical context; and its influence on Arabic in Iraq, Syria and Egypt remain a virgin field to a great extent. There is no scholarly dialogue or connection between the fairly large corpus on the urban development and history of Arab cities and old tribes and the linguistic and historical development of its dialects and varieties (Miller, 2007, p. 178-179). Although scholars of the history of Arabic assume that urban centers were the sources from which the rest of the region was Arabicized and played a major role in the formation and spread of the new varieties of Arabic, they were not able to relate particular structural development to such ecological catalyst. Although the context in which the conquerors' language came in contact with the language of the conquered peoples was always considered important, it was not studied in detail (Abboud-Haggar, 2006, p. 613).

\section{The Argument}

The main argument here is straightforward. From the structural similarities among Bedouin, urban and Classical Arabic in so far as gender is concerned, they can see that all these varieties must have originated from the same source variety. Judging by the pattern and direction of development they will show in this article, all varieties of Arabic must have once in their deeper history expressed gender morphologically on all word classes, and syntactically by complete agreement. There are also some paradigmatic developments common to all three different varieties, such as the lack of gender distinction in the first person in verbs and pronouns. It seems that the loss of gender distinction on relative and demonstrative pronouns in all the dialects is indicative that the dialects are all developing away from Classical Arabic in the same direction in gender. The later development of gender in some dialects in a manner different from that of other varieties and the source variety must have started well before the emergence of Islam, the conquests and the urbanization process, because Bedouin dialects and Classical Arabic share in it. Bedouin dialects stopped at this point, while urban dialects developed further in the gender paradigm. All morphological categories lost the distinction between plural masculine and plural feminine, except nouns. Although Classical Arabic went through a degree of regularization in the first three centuries after the emergence of Islam, it retained gender distinction in all morphological categories. Furthermore, syntactic agreement of feminine plural nouns is masculine plural in these dialects. It will explain towards the end of this article that urbanization caused two contact induced language strategies; koineization and structural simplification. These two strategies must have allowed the urban dialects to develop away from both Bedouin and Classical Arabic. The lack of urbanization in the Bedouin dialects correlates with the lack of gender development in these varieties any further.

The loss of the feminine plural gender distinction in the urban dialects of the conquered territories of the Middle East and North Africa is a by-product of the urbanization of these regions in the seventh century CE. The correlation here between a linguistic development and a socio-demographic phenomenon such as 
urbanization has been made theoretically elsewhere. Al-Sharkawi makes the argument that the combination of a set of non-linguistic ecological factors may cause innovation in the linguistic paradigm of the individual, the speech community and the language community at large. It is previously claimed that the urbanization of the Middle East led to the contact-induced koinization process of the diverse Arabic dialects that took part in establishing and populating each garrison town. They will see in this article that the variable behavior of plural feminine in Modern Arabic, dialects and standard, is only reflective of its behavior during the seventh century CE. Leveling must have played a role in leveling out the discrepancies in gender behavior. The main claim here is that urban dialects lost feminine plural on nouns, verbs, and other word classes as a result of the koineization process. The dialects that did not go through a process of urbanization and its contact-induced strategies did not lose the feminine plural morphological marking on nouns, verbs and other word classes.

In order to make the argument, this article will discuss the feminine plural behavior in the dialect that rose and spread by urbanization. Egyptian Arabic will be studied in detail. Tunisian Arabic will be discussed, albeit with fewer details, because it shows both that the urban dialects are still in a process of development and the direction of development these dialects seem to be taking. The discussion of Egyptian Arabic will show them that like Classical Arabic it has a feminine distinction on the singular noun among masculine, default, and feminine. Unlike Classical Arabic and the Bedouin dialects, the distinction is lost on the plural nouns and the rest of the morphological classes. The article will then discuss gender behavior of the dialects that did not go through an urbanization process. By discussing Najdi Arabic, it becomes clear that it behaves gender wise similarly to Classical Arabic. It has gender distinction between masculine and feminine singular and plural. It has the same distinction on the second and third persons of the verb in the perfective and imperfective and on the demonstrative pronouns and personal pronouns. Najdi Arabic will be compared to the other dialects that have not gone through the urbanization process in the seventh century CE. The Bedouin dialects of Central Asia will then be discussed in order to show that despite heavy restructuring the feminine plural distinction persists in these dialects. Its loss in the other dialects cannot be, theoretically at least, ascribed to substratal influence or any imperfect learning of the language. In the last section, the article will explain the contact induced linguistic strategies that have been triggered by the urbanization process and that they correlate with the development in gender representation in the urban dialects.

\section{Gender in Egyptian Arabic}

Like Modern Standard Arabic and Classical Arabic gender in the Egyptian dialects are expressed on all categories of nouns, verbs pronouns and demonstratives. Unlike Classical Arabic, the dialects lost the relative pronouns as a morphological paradigm, and of course lost gender projection on the single invariable relative pronoun that expresses all genders and numbers. In nouns, gender is expressed in all semantic categories in the singular (Holes, 2004, p. 174). Binary masculine and feminine gender are inherent in the singular nouns. Nouns referring to natural categories bear the two genders, each of which is used according to its referent. Unlike Modern Standard Arabic and Classical Arabic, however, gender is not completely reflected on demonstrative, pronominal, relative, and verbal paradigms. On the syntactic level, gender agreement also differs in the dialects from Modern Standard Arabic and Classical Arabic.

Morphologically, the demonstrative paradigm of the urban dialects is impoverished in number and gender in comparison to its counterpart in Modern Standard Arabic and Classical Arabic, as well as that of Najdi Arabic and other Bedouin dialects. The Demonstrative Paradigm reflects gender in the singular but not in the 
plural (Brustand, 2000, p. 114). In Table 1, you can see the demonstrative pronouns in four major Arabic dialects.

Table 1

The Demonstrative Paradigm in the dialects

\begin{tabular}{llll}
\hline Dialect & Singular Masculine & Singular Feminine & Plural \\
\hline Moroccan & hāda & hādi & hādu \\
Egyptian & da & di & dōl \\
Syrian & hād & dāy & hādōl \\
Kuwaity & hāda & hādi & dēla \\
& & & \\
\hline
\end{tabular}

In addition to these demonstratives, three of the four dialects share a set of unstressed demonstrative articles (Harrell, 1962, p. 147) that come only prefixed to nouns. Egyptian Arabic does not share in that system. This group of articles is in Table 2. Unstressed demonstrative articles, which are sometimes described as anaphoric, do not express gender.

Table 2

Unstressed Demonstrative Articles

\begin{tabular}{ll}
\hline Dialect & Article \\
\hline Moroccan & hād \\
Egyptian & --- \\
Syrian & ha- \\
Kuwaiti & ha- \\
\hline
\end{tabular}

Despite the diversity in the demonstratives among the four previous example dialects, none of them expresses gender on the plural demonstrative form. This suggests that the development in gender, at least in demonstratives, was complete and probably very old in Egyptian Arabic and the other dialects that do not have an unstressed demonstrative paradigm and gender distinction on the plural.

The pronominal paradigm in Egyptian Arabic and the urban dialects in general also lack gender distinction in the first, second and third persons plural. There is, however, a gender distinction in the singular in the second and third persons, as Table 3 indicates. The table shows that first person lacks gender in its singular and plural forms, as was the case in the Classical Arabic variety. In the second and third persons, the gender marking is on the singular only, as opposed to Classical Arabic and which exhibits gender distinction in the singular and plural of the same persons.

Table 3

Independent Pronouns in the Egyptian Dialects

\begin{tabular}{llll}
\hline Person & Singular Masculine & Singular feminine & Plural \\
\hline 1 st & 'ana & & 'ihna \\
2nd & 'inta & 'inti & 'intu \\
3rd & huwwa & hiyya & humma \\
\hline
\end{tabular}

Suffix object and possessive pronouns in the Egyptian and other urban dialects show a similar distribution of gender marking to the independent pronouns, lack of gender distinction in all persons in the plural. Table 4 shows that the first person suffix pronouns do not exhibit gender in the singular and the plural. In the second 
person, gender is only used with the singular reference. So is the case in the third person. It is clear that pronouns behave in the same way as the demonstrative paradigm. In the dialects, there is no paradigm for relative pronouns. A single relative pronoun form is used in the two genders and all numbers in most of the modern dialects of Arabic (Ferguson, 1959, p. 630).

Table 4

Suffix Pronouns

\begin{tabular}{llll}
\hline Person & Singular Masculine & Singular Feminine & Plural \\
\hline 1st & $-\overline{1}$ & & - na \\
2nd & $-\mathrm{ak}$ & $-\mathrm{ik}$ & $-\mathrm{kum}$ \\
3rd & $-\mathrm{u}$ & $-\mathrm{ha}$ & $-\mathrm{hum}$ \\
\hline
\end{tabular}

Gender is expressed only in the second and third persons of the verbs. This happens in the eastern urban dialects, such as Lebanese Arabic (Aoun, et.al., 2010, p. 73-74) and western dialects, in Addition to Egyptian Arabic. Moroccan Arabic, on the other hand, lost the gender distinction on the second person verb in the perfective but retained this distinction in the imperfective. Table 5 shows that the first person singular and plural do not express gender. Second and third persons singular distinguish between feminine and masculine persons by means of a prefix in the imperfective and a suffix in the perfective. However, second and third person plurals do not distinguish feminine from masculine persons (Benmamoun, 2000, p. 23). Otherwise, both Moroccan and Egyptian Arabic agree with Classical Arabic in distributing gender agreement in perfective and imperfective verbs. The following table is (Benmamoun, 2000, p. 22):

Table 5

Verbs

\begin{tabular}{lllll}
\hline Person & Number & Gender & Perfective & Imperfective \\
\hline 1st & singular & $\mathrm{M} / \mathrm{F}$ & katabt & 'aktib \\
1st & plural & $\mathrm{M} / \mathrm{F}$ & katabnā & niktib \\
2nd & singular & $\mathrm{M}$ & katabt & tiktib \\
2nd & Singular & $\mathrm{F}$ & katabtī & tiktibī \\
2nd & plural & $\mathrm{M} / \mathrm{F}$ & katabtū & tiktibū \\
3rd & singular & $\mathrm{M}$ & katab & yiktib \\
3rd & singular & $\mathrm{F}$ & katabit & tiktib \\
3rd & plural & $\mathrm{M} / \mathrm{F}$ & katabū & yiktibū \\
\hline
\end{tabular}

It seems from the above that the urban Egyptian dialects and Classical Arabic are similar in gender as far as the singular verbs and all kinds of pronouns are concerned. Both varieties do not have a gender distinction in the first person singular verb and pronouns. In the other morphological paradigms the dialects kept, there is the same gender distinction of Classical Arabic. However, the loss of the dual in all morphological paradigms and the lack of gender distinction on plurals of all morphological paradigms set the dialects apart from Classical Arabic.

As far as nouns are concerned, the issue of gender is more complicated in the Egyptian dialects and in Classical Arabic. They have to deal with factors that have to do with animacy, humanness, and word classes. Nouns referring to humans, natural gender, are inherently gendered in all varieties. They may not change the phonological and morphological gender suffix marker. The feminine marker for the feminine gender in the dialects is - $a$, that is suffixed to the noun, exactly like Modern Standard Arabic and Classical Arabic. As far as 
natural gender category is concerned, there is a complete affinity between the dialects and Classical Arabic. Nouns referring to humans, such as professions, kinship terms, and titles. These nouns are not distributed in noun classes. These nouns can acquire the feminine $-a$ marker if they refer to a feminine referent, as in (1) below:

(1) duktōr duktōr-a

doctor-m doctor-f

$\begin{array}{ll}\check{s} a b b & \check{s} a b b-a \\ \text { young man } & \text { young woman }\end{array}$

Morphologically speaking, both natural gender nouns and nouns referring to humans have a morphological marker for the plural feminine in the form of a suffix $-\bar{a} t$. In (2) you can see the plural feminine of the nouns in (1):

(2) duktōr-a duktōr-āt

doctor-f-s doctor-f-p

$\check{s} a b b-a \quad \check{s} a b b-\bar{a} t$

young woman young women

Both classes of nouns reflect gender in the clause level and on the sentence level in the singular but not in the plural as follows:

(3)

bint gamīl-a

a girl-s-f beautiful-s-f

a beautiful girl

(4)

duktōr-a kuwayyis-a

doctor-s-fgood-s-f

a good doctor

(5)
di $\quad$ duktōr-a
this-s-f doctor-s-f
this is a doctor

(6)
di amm-a
this-s-f aunt-s-f
this is an aunt

In (3) and (4) the adjective following the noun is in the feminine singular ending with the suffix $-a$. In (5) and (6) the demonstrative preceding the noun in the phrase is also in the feminine singular. Complete agreement goes beyond the noun phrase, as in (7) and (8) below: 
(7)

$$
\begin{aligned}
& \begin{array}{l}
i l-\check{s} a b b-a \quad \text { bitnām } \\
\text { the young woman-s-f } \\
\text { the young woman sleeps }
\end{array}
\end{aligned}
$$

(8)

$$
\begin{array}{ll}
i d-d u k t o \bar{r}-a & \text { nisyyit } \\
\text { the doctor-s-f } & \text { forgot-3rd-s-f } \\
\text { the doctor left } &
\end{array}
$$

The verb phrase agrees with the preceding noun phrase in gender as well as person and number in (7) and (8). Although there are plural feminine nouns in natural gender nouns and in nouns referring to humans, there is, unlike Classical Arabic, no plural feminine agreement. The agreement pattern is incomplete. The following examples reflect a masculine plural agreement in Egyptian Arabic:

(9) sitt-ät muslim-īn

women-p-f Muslims-p-m

Muslim women

(10) humma muhandis-āt

they-p-m engineer-f-p

they are engineers

(11) il-muslim- $\bar{a} t \quad$ bi-yilbis- $\bar{u} \quad$ hiğ $\bar{a} b$

muslims-p-f wear-3rd-p Hijab

Muslim women wear Hijab

In (9) the agreement between the noun and the following adjective is incomplete, as the adjective is in the plural masculine while the noun is in the plural feminine. In (10) the independent pronoun is in the un-gendered plural while the following noun is in the plural feminine. In (11) the verb phrase starts with a head verb in the third person plural masculine while the preceding noun phrase is in the plural feminine.

Inanimate nouns and nouns referring to non-humans have two broad classes in the singular: a class that ends with -a morpheme of the feminine gender and a category that does not. The dialects agree with Classical Arabic in these two classes. The agreement patterns of the noun classes are identical in the dialects Classical Arabic. In the singular there is a complete agreement on the phrase and sentence levels, as in (12) and (13) below:

(12) kurrās-a kibirr-a

notebook-s-f big-s-f

a big notebook

(13) $k$ kurrās-a itramit

notebook-s-f was thrown-3rd-f-s

a notebook was thrown away 
Inanimate nouns behave in a similar way as human nouns in the dialects and Modern Standard Arabic and Classical Arabic in the singular. The adjective in (12) agrees with the preceding feminine singular noun. In (13) the verb agrees with the preceding subject and person, number and gender. However, in the plural, nonhuman and inanimate nouns do not have a gender distinction. Several types of plural morphemes exist, one of which is the human plural morpheme $-\bar{a} t$. In addition, these nouns do not agree. Within the phrase and on the sentence levels the agreement is in the feminine singular, as in (14) and (15) below:

(14) kumbyūtar-āt kibìr-a

computers-p big-f-s

big computers

\section{(15) kumbyütar-āt}

itramit

computer-p was thrown-3rd-f-s

computers were thrown away

In (14) the head noun is in the feminine plural, while the adjective is in the feminine singular although the singular form of the head noun does not end in the feminine -a morpheme. In (15) the verb does not agree in number or gender with the preceding noun. The agreement pattern shown in the previous two examples is a common pattern among the dialects on the one hand and Classical Arabic on the other.

In both the dialects and Classical Arabic the feminine plural ending of primitive nouns and verb-derivatives is unpredictable (Holes, 2004, p. 168). Some noun types end in -āt in the plural although they are not nouns ending in $-\mathrm{a}$ in the singular form. It is also the ending for many non-human noun categories as well as the standard plural for loan words. Nouns derived from form VI verbs CVCVVCVCV, such as taqäbul "meeting" ends in the plural in the feminine ending -āt taqābul-ät. The same happens with form VII verbs n-CVCVCV such as $n$-kisār "breaking", which becomes in the plural n-kisār-āt. The same phenomenon happens in forms VIII and X. Loan words in general have $-\bar{a} t$ as a plural marker in general. A word like kumbiyutar is masculine in the singular, but ends as kumbiyuttar-ät in the plural.

In addition, the singular feminine $-\mathrm{a}$ is sometimes suffixed to masculine nouns to express the plural masculine in both the dialects and Classical Arabic. Form active participles referring to humans on the form CAACiC such as qātil "killer" go to qatal-a "killers" in the plural and māhir "skilled" goes into mahar-a "skilled people". The feminine counterparts of these nouns are suffixed by the plural feminine $-\bar{a} t$ marker. $K \bar{a} t i b$ and māhir go to kātib-āt and māhir-āt respectively. So both feminine forms in Arabic are used to express masculine plural noun classes.

\section{Tunisian Arabic}

The urban dialect of Tunis will not be described here in great details. It shares with the other urban dialects the general behavioral features of gender morphologically and syntactically. Therefore, it will not discuss its gender agreement patterns on the syntactic levels. Neither will it discuss its morphological gender features that stand in alliance with the other urban Arabic dialects. One unique aspect of Tunis Arabic will be mentioned here in order to indicate that the direction of development urban dialects may take. Tunisian Arabic is used here as an example for a group of North African dialects that share the same morphological trends. The point in 
focus here is the loss of gender distinction on the second person pronoun and verb and the demonstrative paradigm. This phenomenon is common among the Tunisian dialects and Maltese (Gibson, 2009, p. 565).

The dialect of Tunis does not have a gender distinction at all on any pronominal paradigm, independent or suffix, leaving the total number of pronouns at seven. Gender distinction happens only on the third person singular, and no gender distinction happens on the plurals. Gender seems also to be in a variable state in the demonstrative paradigm. The usual demonstrative pronoun for masculine and feminine alike is had. There is, however, a gender distinction between masculine and feminine singulars when a discursive or pragmatic contrasting is needed. In such cases, an additional had̄aya/ha $\underline{d} a$ for masculine or ha $\underline{\bar{t}} \bar{y} a / h \bar{a} \underline{d} i$ for feminine is added after the noun following the demonstrative (Gibson, 2009, p. 564). Interestingly, distal demonstrative pronouns show two types: one type before the noun, hak. This is an invariable demonstrative. The second type

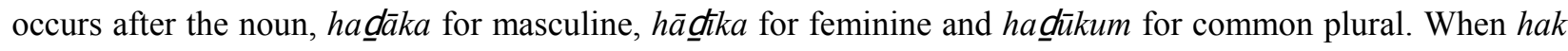
is used, it comes before a masculine noun, a feminine noun, or even a plural noun. The case is different in the second type that makes a gender distinction in the singular only.

In the verbal paradigms, like pronouns, there is no gender distinction between feminine and masculine in the second person. The phenomenon happens in the perfective and imperfective tenses alike. The only gender distinction in Tunisian Arabic verbs is in the third person singular perfective and imperfective (Gibson, 2009, p. 568).

They can summarize the morphological status of the gender paradigm as they can see from the previous paragraphs as follows: in the Egyptian dialects the demonstrative, pronominal, nouns, and verbal paradigms retained gender in the singular and lost it in the plural. In pronouns and verbs the first person lost the gender distinction all together. Pronouns and verbs lost second and third persons plural distinction between feminine and masculine as well. Furthermore, the relative pronoun lost its paradigmatic status with any gender distinction. In Classical Arabic morphological representation of gender, these paradigms have a relatively more elaborate gender representation. Some of them more complete representation than others. The paradigm for relative pronouns is complete; it expresses gender in all numbers, which is a stark opposition to relativization in the dialects. Demonstratives and pronouns are, by contrast, incomplete. The demonstrative paradigm expresses gender in Classical Arabic in singular and dual, but not in the plural. In pronouns, first person singular and plural does not express gender. In 2nd and 3rd persons of Classical Arabic gender is expressed in the singular and plural. Number carries gender expression in the dual. However, these two paradigms are more elaborate than their dialectal counterparts.

Morphologically speaking, the nouns in Modern Standard Arabic and Classical Arabic are identical to the noun categories of the dialects - urban and Bedouin. The morphological gender suffix behaves almost identically in both varieties in the singular. Human nouns and nouns referring to humans in both varieties end in the feminine suffix if the referent object is feminine. Inanimate and nonhuman common nouns are arbitrarily gendered, and in the same way in both varieties. In the plural both varieties add the plural feminine suffix $-\bar{a} t$ to human nouns and nouns referring to humans. Inanimate and nonhuman plurals also receive the feminine plural suffix in the plural in both varieties. Both varieties also share in the phenomenon of using the feminine singular and plural suffixes with masculine noun classes. The feminine singular suffix $-a$ is given to some noun classes to express the plural. The plural feminine suffix is attached to some nouns to express the plural. The difference between nouns in both varieties is also syntactic and not only morphological. While both varieties put nonhuman and inanimate nouns in feminine singular agreement, they differ in human nouns and nouns 
referring to humans. There is no plural feminine agreement in the dialects, although there is number agreement. The human feminine plural nouns receive masculine agreement in the urban dialects in general on the phrase and sentence levels. In Modern Standard Arabic and Classical Arabic agreement is complete on the phrase and sentence levels. Human feminine plurals receive feminine plural agreement.

A quick comparative look at the gender paradigm shows that it is more resilient in Classical Arabic than in the Egyptian dialects and type three dialects in general. But among resilient structures in Classical Arabic, it is less resilient than other structural phenomena, such as the dual paradigm for example. The dual paradigm is projected on demonstratives, pronouns, relative pronouns, verbs, and nouns on the morphological level. Syntactically, all categories of nouns receive dual agreement in the two genders. Full agreement functions on the phrase and clause levels. In comparison, gender is less resilient than the dual for two reasons: In the first place, with the exception of relative pronouns, all morphological paradigms are incomplete in gender representation. In the second place, the feminine markers $-a$ and $-\bar{a} t$ for singular and plural respectively are not exclusively gender markers. Some noun categories accept feminine agreement in the plural although they do not receive the feminine suffix $-a$ in the singular. Nonhuman and inanimate nouns receive feminine singular agreement in the plural in both the dialects Classical Arabic, as in (16) and (17) below:

$$
\begin{array}{ll}
\text { al-makātib } & \text { kabīra } \\
\text { the offices-p-m } & \text { big-s-f } \\
\text { offices are big } &
\end{array}
$$

(17) il-tirān

bi-timš̄ bi quwwa

the bull-p-m run-3rd-s-f with power

bulls run quickly

In (16) the subject noun phrase of the sentence (from Modern Standard Arabic) is a masculine plural noun and the predicate noun phrase is an adjective in feminine singular agreement. In (17) the subject noun phrase is a nonhuman noun in the plural masculine, while the verb phrase is headed by a verb conjugated in the third person singular feminine. In addition, some noun categories receive a feminine plural marker $-\bar{a} t$ although they in the singular do not receive the singular feminine suffix morpheme. Most prominent among these categories are loan words. They will conclude this part by saying that the use of feminine suffixes with masculine noun classes in the dialects and Classical/Modern Standard Arabic indicates that the morphological representation of gender is noisy. Some masculine nouns referring to humans end with the feminine singular marker in the plural. In addition, some inanimate masculine nouns end in the plural with the feminine plural ending.

The discrepancies in the morphological paradigms of Classical Arabic correspond to the areas in the urban Egyptian dialects where the feminine gender is lost. In the demonstratives, Classical Arabic does not have a plural feminine, and the dialects do not have a plural feminine. In pronouns the dialects do not have a dual gender distinction, and so does Classical Arabic. In the dialects there is no dual feminine, the dual marker in Classical Arabic is the same in feminine and masculine. In pronouns and verbs there is no 1st person singular gender distinction in both varieties. These similarities indicate that both varieties were moving in the same direction of development before the development in the ancestor of Classical Arabic was arrested during the standardization period. 
The following section will show them that the morphological and syntactic representation of gender in the Bedouin dialects and the type two dialect in general and Najdi Arabic in particular is more similar to Classical Arabic than to urban dialects.

\section{Gender in the Arabian Peninsula}

The main focus in this section is Najdi Arabic as a representative of the old Bedouin dialects, and a dialect that ranks second after Classical Arabic on the continuum of complexity/simplification according to Kusters, as it is less economical than Egyptian Arabic and, certainly, Tunisian Arabic in gender representation. It chose Najdi Arabic as the focus here because it is large and diversified archaic dialect area that is not isolated geographically or socially from other dialect types (Ingham, 2008, p. 326-334). Its geographical location and the mobility of its users allow it to come in contact with other dialects. But despite this contact it retains the gender features as well as its other archaic features. In addition, along the description, it will refer to other peninsular and non-peninsular dialects that share the Najdi dialect features. By doing this, they hope to show that the archaic gender behavior is not unique to this dialect group. That is, gender in Najdi Arabic does not make it an island. It persisted in all the dialects that did not go through an urbanization process like Egypt, Iraq and Syria. Geographically, the Najdi dialects contain the speech of the urban areas of Central Najd, al-Qasim and Jabal Shammar in the North and Najran and Bīsha in the south. It also contains the speech of the Bedouin groups of the same regions as well as the speech of the migrant Bedouin tribes of the Syrian deserts and al-Jazīra in Iraq (Ingham, 2008, p. 326). The dialects of this vast area are connected syntactically and lexically to the dialects of Yemen and Oman in the south and Eastern Arabia in the east. This vast linguistic area is open to the other geographical and dialectal areas of the Arabian Peninsula. Najdi Arabic belongs in a geo-political entity, Saudi Arabia, which is famous for its dialectal diversity. However, Najdi Arabic is the largest dialect group in the region (Ingham, 2009, p. 130).

Linguistically, the Najdi dialect group reflects a high degree of archaisms, which give the impression of approximation to Old/Classical Arabic. Archaisms exist on all levels of linguistic analysis. Phonologically, Najdi dialects retain the distinction between $/ \underline{t} /$ and $/ \underline{d} /$ and between dentals and interdentals. Morphologically, the Old Arabic indefinite article suffix -in is retained at the end of nouns, verbal particles of Old Arabic such as qid is retained, the verbal system of Old Arabic is retained, but the aspectual prefix markers of the verbs in other dialects are missing. Syntactically, the internal passive is prevalent (Ingham, 1994, p. 6). This archaic group is structurally related to the dialects of Yemen and Oman in the south, the dialects of Eastern Arabia in the east and the Northern dialects of Jordan and Iraq in the north. The desert flat terrain allows the dialects users, especially Bedouin dialects to move along the whole peninsula (Ingham, 2009, p. 123). In spite of the easy flow of tribes, the dialect area retains its archaic nature probably because of the lower migration waves (Ingham, 1994, p. 7) and the lack of urbanization processes that took place on its land. It is, therefore, very important to look at the dialects of the Peninsula as a whole, especially because various dialects reflect diverse structural features (Ingham, 2009, p. 124). The same features can be reported in areas far apart from one another, and can appear in one area and not in the dialect of an adjacent area, and the case of the feminine plural is an example.

This archaic nature is reflected in the gender behavior of the dialect group. Morphologically speaking, gender is represented on perfective and imperfective verbs, and also on the imperative verbs. This gender distinction is not only reserved to the Najdi Bedouin dialects but also in some of the Yemeni dialects as well, 
where a gender distinction appears on the second and third persons plural (Watson, 2009, p. 114). The same gender function is also functional in the Bedouin dialects of the Sinai Peninsula (De Yong, 2009, p. 241). In the following table, they can see feminine distinction between second person singular and plural and third person singular and plural and Najdi and non-Hijazi dialects (Pochazka, 1988, p. 24) and eastern Arabian dialects (Johnstone, 1967, p. 42):

Table 6

Najdi Arabic Verbs

\begin{tabular}{llll}
\hline Person & Perfictive & Imperfective & Imperative \\
\hline 3rd sing. m. & Kitab & ya-ktib & \\
3rd fem. F. & Ktib-at & ta-ktib & \\
3rd pl. m. & ktib-aw & ya-ktib-ūn & \\
$3^{\text {rd }}$ pl. f. & ktib-an & ya-ktib-in & \\
2nd sing. m. & kitab-ta & ta-ktib & iktib \\
2nd sing. f. & kitab-ti & ta-ktib-in & iktib-i \\
2nd pl. m. & kitab-tu & ta-ktib-ūn & iktib-ū \\
2nd pl. f. & kitabt-in & ta-ktib-in & iktib-in \\
\hline
\end{tabular}

This table shows that the feminine gender is projected on the second and third persons singular and plural, as is the case in Classical Arabic. Also like Classical Arabic, and the urban dialects for that matter, there is no gender distinction in the 1st person. Unlike Classical Arabic, however, there is a paradigmatic lack of representation of the dual and gender on it. Conjugation suffixes at the end of the perfective and imperfective verbs respond to their inflectional environment. These morphemes show modification when followed by object pronoun morphemes. The $-n$ sound at the end of the second and third feminine and masculine nouns is doubled before object pronouns. The short vowels of these suffixes are lengthened. The conjugation morpheme in ktib-an "they f. pl. wrote" goes into ktib-ann-ih "they f. pl. wrote it m. s.". Similarly, the suffix in ikitb-u "write" in the imperative goes into the lengthened $i k i t b-\bar{u}-h$ "write it" in the environment of the object pronoun (Ingham, 1994, p. 22). The presence of gender distinction on the second and third persons plural and on imperatives is by no means prevalent in the dialects of Saudi Arabia. While this is a Najdi and Eastern Arabian phenomenon, the Hijaz region, Najran, Rufaida, Abha, Riyadh, Hufuf, and Bisha have a common plural and no gender distinction (Prochazka, 1988, p. 24).

As far as nominal morphology is concerned, gender in Najdi Arabic is expressed on the singular and plural nouns. Number and gender categories in Najdi Arabic generally follow the rules of Classical Arabic, albeit with slight modification (Prochazka, 1988, p. 61). Feminine plural nouns end in -āt (Holes, 1990, p. 148). Gender distinction is also fully functional in the pronoun paradigm. This gender distinction is not only present in Najdi Arabic, but also in the Saudi Arabian dialects, except the Hijazi type, and Eastern Arabian dialects in general. It is also present in some Yemeni dialects, such as the șan'āni dialect, where there is a distinction between third person plural feminine and masculine independent subject pronouns (Watson, 2009, p. 110). The same distinction is also present in the dialects of Sinai (De Yong, 2009, p. 245-246). Independent pronouns in Najdi Arabic and the other Bedouin dialects, like verbal affixation, projects gender on second and third person singular and plural nouns (Prochazka, 1988, p. 125). In addition, suffix pronouns also project the same gender distinction in the second and third persons in the plural (Prochazka, 1988, p. 126). 
Table 7

Suffix Pronouns

\begin{tabular}{llll}
\hline The pronoun & Translation & The Pronoun & Translation \\
\hline Šāf-ni & he saw me & šăf-na & he saw us \\
Šāf-ik & he saw you m & šăf-ic & he saw you f. \\
Šāf-kum & he saw you m. pl. & šāf-cin & he saw you f. \\
Šāf-ih & he saw him & šăf-ha & he saw her \\
Šăf-hum & he saw them m. & šăf-hin & he saw them f \\
\hline
\end{tabular}

This table indicates that with the exception of first person all persons and numbers express the feminine gender. Independent personal pronouns carry the same distinction on the second and third persons in the plural:

Table 8

Personal Pronouns

\begin{tabular}{lll}
\hline Person & Masculine & Feminine \\
\hline 1 st s. & ana & \\
1 st pl. & hinna & \\
2nd s. & anta & anti \\
2nd pl. & antum & antin \\
3rd s. & hu & hi \\
3rd pl. & hum & hin \\
\hline
\end{tabular}

This table shows a complete gender distinction on the existing number paradigms in this dialect group like Classical Arabic.

Also like Classical Arabic, demonstrative pronouns also express gender distinction. Despite variation in the existence of a final vowel and/or the ha- element, gender is a stable phenomenon in the Najdi group of dialects (Ingham, 2009, p. 329):

Table 9

Demonstrative Pronouns

\begin{tabular}{|c|c|c|}
\hline Number & Masculine & Feminine \\
\hline \multicolumn{3}{|l|}{ This } \\
\hline Singular & hāḍa/da & hādidi/di i \\
\hline Plural & hā̄ōōa/hadōōl & hadōōli \\
\hline \multicolumn{3}{|l|}{ That } \\
\hline Singular & d्āā/had̄āk & dīìc/hādīīc \\
\hline Plural & dōōlāk/hadōōlāk & dōolīe/hadōōlīc \\
\hline
\end{tabular}

The two types of demonstratives show gender distinction. Although Șan'āni Arabic shares gender distinction with Najdi Arabic in nouns, pronouns and verbs, its gender distinction in the demonstrative paradigm is incomplete. Șan'āni Arabic has two sets of demonstratives: one with initial hā- and one without it. Gender distinction in the plural exists on the category that does not have an initial $h \bar{a}$ - in either near or distal forms. The demonstrative pronouns with the initial $h \bar{a}$ - do not have a gender distinction in the plural in both near and distal forms (Watson, 2009, p. 110-111). In the following two tables, they will show the behavior of gender on demonstratives: 
Table 10

Near Demonstratives with hä-

\begin{tabular}{lll}
\hline Gender & Singular & Plural \\
\hline Mas. & hā̄a & hādawlā \\
Fem. & hādi & \\
\hline
\end{tabular}

Table 11

Near Demonstratives without hā-

\begin{tabular}{lll}
\hline Gender & Singular & Feminine \\
\hline Mas. & dayyā & hādawlāk \\
Fem. & Tayyih & dawlayyā \\
\hline
\end{tabular}

The same pattern of gender distinction on the plural happens between distal demonstrative pronouns that have $h \bar{a}$ - and those that do not (Watson, 2009, p. 111). There is no gender distinction in the Sinai dialects in demonstrative plurals except in the dawaghra dialect, which comes from a central Najdi origin. Other non-Najdi dialects do not reflect gender distinction in the plural (De Yong, 2009, p. 245). The only word class that reflects gender distinction in Classical Arabic but not in Najdi dialects is the class of the relative pronouns. Najdi Arabic and other Eastern Arabian Dialects share the form illi "who/which" and ma "what" as non-responsive forms as opposed to the fully numbered and gendered forms of Classical Arabic (Johnstone, 1967, p. 67). The Yemeni dialects also do not reflect gender distinction on the relative pronouns. Bedouin Sinai dialects also do not reflect a gender distinction (De Yong, 2009, p. 246-247). In fact the relative pronoun in Yemeni dialects, Najdi dialects and urban dialects lost its paradigmatic status, which is retained in Classical Arabic.

Syntactically speaking, concord patterns generally follow the patterns of Classical Arabic albeit with some modifications (Ingham, 1994, p. 61). Although gender is shown on all morphological categories, sometimes, masculine plurals stand for a common plural as in urban dialects. However, patterns of concord show a great variation among the Najdi dialects themselves. Variation in concord is not limited to Najdi dialects. Gulf dialects in general exhibit a considerable degree of variation (Holes, 1990, p. 155-156). There is, in addition, plenty of personal variation, due to the fact that speakers of Najdi Arabic often come in contact with speakers of other dialects (Ingham, 1994, p. 61). Among the most important points of variation they are two that have to do with feminine plurals: the presence/absence of the plural feminine affixes on the verb and its associated independent pronouns (intin and hin), and the presence/absence of the feminine plural suffix -ât in adjectives as modifiers (Ingham, 1994, p. 61).

Concord operates within the sentence or the clause. Verbs and adjectives agree with the head noun. Generally speaking, the number and gender of a noun are copied to the adjective and/or verb that follow it. Agreement with dual nouns is in the plural and inanimate nouns receive feminine singular agreement (Ingham, 1994, p. 62). In the following adjectival phrase, they can see the agreement pattern between a head noun in the feminine plural and an attributive adjective (Ingham, 1994, p. 63):

$\begin{array}{ll}\begin{array}{ll}\text { Niswān-in } & z \bar{e} n-\bar{a} t \\ \text { Women } & \text { nice-plural-f. } \\ \text { good women } & \end{array} & \end{array}$


In this example, the adjective follows the noun in gender and in number, exactly like concord rules of Classical Arabic, and unlike concord in urban dialects, where the adjective receives plural masculine agreement.

Although generally speaking, verbs agree with feminine plural head nouns, some people do not make gender distinction on plural verbs. In these cases, the plural masculine ending - $\bar{u} n$ marks a common plural. This exception is age-related. Older generations tend to observe the full gender concord between the verb and its agent noun, while younger generations tend to use the common plural form more. In addition, avoidance strategies can be observed where the speaker uses a VS order instead of the SV order to avoid the feminine plural marker on the verb. Furthermore, there is a common inter-dialectal form that resembles a koine that educated speakers use among one another when more than one person from different dialectal background communicate. In this style, the second and third persons plural feminine is missing. This fact shows that the feminine plural is not a privileged form, although it is represented morphologically (Ingham, 1994, p. 66).

\section{Central Asian Arabic}

In this section it will introduce gender behavior in the Central Asian Arabic dialects to show that despite heavy contact with local languages, scarcity in number, less prestige, and heavy areal borrowing, gender distinction in the plural between masculine and feminine is retained. It seems that it is only through koineization that a variety looses gender distinction, as they have seen above. The Arabs of Afghanistan live in four villages: Two of them are in Mazār Sharīf (102 and 16 families), and the other two are in Shibārghan (Ingham, 2006, p. 28). These dialects show a strong influence from the surrounding languages of the area, Dari, Pashtu and Uzbek. It, therefore, has many phonological, morphological and syntactic features not found in other dialects of Arabic (Ingham, 2006, p. 28). By the same token, the speakers of the two Uzbekistan Arabic dialects communicate with each others in Tajik or Uzbek because of the heavy restructuring that befell the variety. In spite of this, the two varieties retained gender distinction on all morphological categories, except the relative pronouns, which lost their paradigmatic status.

Morphologically speaking, the Afghanistan dialect of Arabic has a paradigm of personal pronouns that represents gender on the second and third persons plural, the dual category being lost from all morphological word classes except nouns. Suffix object pronouns also show the same distinction, as the following table shows:

Table 12

Suffix Pronouns in Afghanistan Arabic

\begin{tabular}{lll}
\hline Person & Singular & Plural \\
1st & $-n i$ & $-n a$ \\
2nd masc. & $-(a) k$ & $-k u m$ \\
2nd fem. & $-k i$ & $-k i n$ \\
3rd masc. & $-\mathrm{u}$ & -hum \\
3rd fem. & $-(\mathrm{h}) \mathrm{a}$ & -hin \\
\hline
\end{tabular}

In the pronominal paradigm of Uzbekistani Arabic, there is a gender distinction between second and third persons plural (Zimmerman, 2009, p. 615). The following table shows a formal similarity between the Uzbekistan Arabic and the Najdi pronominal paradigm: 
Table 13

Independent Pronouns in Uzbekistan Arabic

\begin{tabular}{lll}
\hline Person & Sigular & Plural \\
\hline 1st & anā & nahnā \\
2ndmasc. & hint & hintu \\
2nd fem. & Hinti & hintin \\
3rd masc. & hāt & halo \\
3rd fem. & Hai & halān \\
\hline
\end{tabular}

Gender distinction also exists on the second and third persons plural of the object and possessive suffix pronouns (Zimmerman, 2009, p. 615). Unlike the demonstrative pronouns in Șan'āni Arabic and Bedouin Sinai dialects, near and distal demonstrative pronouns in the Central Asian dialects reflect gender distinction on the plural (Zimmerman, 2009, p. 616). Gender distinction is also functional on the verbal paradigm. Perfective and imperfective verbs distinguish in gender between second and third persons plural (Zimmerman, 2009, p. 618), so does the imperative verb, which is derived from the imperfective (Fischer, 1961, p. 253). Gender distinction is made on the perfective and imperfective verbs on the second and third persons plural, as in the following table (Ingham, 2006, p. 31):

Table 14

Verbs in Afghanistan Arabic

\begin{tabular}{|c|c|c|c|c|}
\hline Person & Gender & Number & Perfective & Imperfective \\
\hline $1 \mathrm{st}$ & ------ & singular & katabt & maktib \\
\hline $1 \mathrm{st}$ & ------ & plural & katabna & niktib \\
\hline 2nd & masculine & singular & katabt & tiktib \\
\hline 2nd & feminine & singular & katabti & tiktibīn \\
\hline 2 nd & masculine & plural & katabtu & tiktibūn \\
\hline 2 nd & feminine & plural & katabtin & tiktibin \\
\hline $3 \mathrm{rd}$ & masculine & singular & katab & miktib \\
\hline $3 \mathrm{rd}$ & feminine & singular & katabit & tiktib \\
\hline $3 \mathrm{rd}$ & masculine & plural & katabu & miktibūn \\
\hline $3 \mathrm{rd}$ & feminine & plural & katabin & miktibin \\
\hline
\end{tabular}

\section{Urbanization and Language Development}

It has been suggested elsewhere (al-Sharkawi, 2013) that the socio-demographic circumstances of the early Arab conquests of the Middle East and North Africa were conducive to the inception of a koinezation process. In addition, migration of Arabs from different dialectal backgrounds to these towns led to constant and continuous contact among the dialects, which in turn led to a long-term dialectal accommodation - a linguistic convergence which occurs in speech communities that change their place of residence permanently. Because of the stability of the migration types and scarcity of influx, contact situation among the dialects of Arabic in garrison towns led to durable and gradual language change among the contact dialects, as is common in contact situations in general (Auer, 2007, p. 109-110), or enhanced developments that were already in motion in previous times. The case of the feminine gender is one such enhanced development. This change, they further argue, led to the formation of a new dialect or a koine, which must have been somehow different in each garrison town, according of course to the difference in contact dialects (Tuten, 2007, p. 185). The establishment 
of the new Arab camps and their growth into towns and the stability of their status allowed the fairly homogeneous tribal groups to come together. Al-Maqrizi (1364-1442 CE) lists for them the branches of Arab tribes that took part in the conquests of Egypt. From the list they can deduce that they were mostly from south and southeastern Hijaz. The limited data they have from this part of the Peninsula before the Arab conquests do not show a high degree of variation (al-Sharkawi, 2008, p. 698-699). Al-Sayyad also states that Tamim and Bakr people, whose original linguistic differences were minimal, inhabited Basra (al-Sayyad, 1991, p. 47).

In addition to leveling, the newly formed varieties were further simplified by Arabs in their attempts to communicate with the local migrant workers and farmers. One could safely assume that since the tribes that lived in the Arab garrison towns in Egypt came from Hijaz and Yemen, some of them must have had a gender distinction such as that in some Yemeni and Najdi dialects, and some not, judging of course by the behavior of these dialects in the modern times. In addition, agreement patterns must have been complicated; the simplification of Foreigner Talk registers must have reduced the plural feminine agreement into the common agreement pattern found in Egyptian and other urban dialects.

Let them now consider the two contact-induced strategies in more detail. The idea of a koine is not new to the field of the history of Arabic; it has come a long way. It has been sometimes suggested as a product of pre-Islamic constant contact between Arab mercantile tribes and neighboring non-Arabic speaking nations, and at other times as a product of the conquests. Corriente suggested that a process of koineization must have existed in pre-Islamic times in the Nabataean areas in North West Arabia among the Arab tribes that were engaged in trade between north and south (Corriente, 1976, p. 62-98). These groups were mostly sedentary people who lived in the cities of Northern Arabia. The claim was that it spread along the trade routes of North West and South West Arabia and along the Hijaz region. Its structural features were claimed to have appeared in pre-Islamic Arabic documents; the most important feature of which is the loss of the case system (Abboud-Haggar, 2006, p. 617). Janssens concurs and asserts that this koine carried both Western and Eastern features (Janssens, 1972, p. 9-16). Both scholars also agree that it was the lingua franca used in the new urban centers of the Middle East and was, therefore, the source of the Modern dialects of Arabic.

Two points of criticism can be raised against this conceptualization of a pre-Islamic koine. Historically speaking, though the idea is theoretically plausible, they have no evidence that such a variety was formed or could have been formed. Any detailed description of a possible contact situation between dialects such as the one given in al-Sharkawi (2013) is not easy to attain due to the lack of accurate historical data. In addition, provided such a koine existed, they have no evidence, historical, anecdotal, or even linguistic that it spread beyond its original locus. The important point here is not to deny such a phenomenon, however. They suggest that it is an irrelevant theory in the formation of the Arabic dialects in the conquered territories. The tribes that migrated to Egypt, for instance, are from Hijazi, Yemeni and Najdi tribes that were geographically distant from the potential locus of the presumed koine. In addition, they did not belong, except in few cases, to tribes involved in any mercantile life style in pre-Islamic times.

Linguistically speaking, dependence on the case system as an indicator for a possible process of leveling in pre-Islamic times is inadequate and fairly confusing. It seems that the case system was in a state of innovation in pre-Islamic times and this innovation took different shapes in different dialects. They know for instance that in Yemeni dialects: 1) the dual ending - $\bar{a} n i$ was invariable, and therefore insensitive to case, 2) the demonstrative particle, it seems, was also case insensitive, and 3) the relative pronoun was also insensitive (al-Sharkawi, 2010, p. 45). Other dialects also treated the dual ending invariably, such as Dabba in the north 
west of the Empty Quarter. In Dabba, the dual marker must have been -āna, which is a different treatment of the final short vowel. Other tribes in the same broad region of the peninsula and on the trade route between Hijaz and Yemen also treated the case system in a different manner. Azd, for instance, retained the case system for nouns even in pause position (al-Sharkawi, 2010, p. 45). In Hijaz, Arab grammarians tell them that: 1) the dual marker was invariable like Yemen, 2) after 'inna and its sisters, the subject and the predicate of the nominal sentence were in the accusative case, 3) after kāna and its sisters, the two parts of the nominal sentence were in the nominative case, and 4) after the alleviated 'an and 'in the noun was given an accusative case (al-Sharkawi, 2010, p. 48-49).

From the examples above, we can see, against Corriente's suggestion, that there was a case system in pre-Islamic Arabic dialects, albeit in a state of development. The examples also show, contrary to any potential regularization and leveling effect of a koine, that the development in the case system took different forms in different tribes. It is also remarkable that Hijaz on the trade route had a case system. If there were a pre-Islamic koine, its dissemination must have been thought to be the Hijaz trade route, but examples testify to the contrary. Equally remarkable, judging by invariable morphological features is the tendency of dialects, such as Dabba, that were not on the trade routes to innovate in the case system.

Ferguson also postulates a koine as a source for New Arabic dialect features. But he, correctly, did not share the notion that it could have originated in pre-Islamic Arabia. He, in harmony with the analysis suggested in ecological research, rather asserts that it started in the military camps of the early conquests. He describes this koine as a relatively homogeneous new variety, not based on a single pre-Islamic dialect, which developed as a language of communication after the conquests. Although the origins of this koine could have existed in pre-Islamic times, it grew in and spread from the garrison towns and formed the origins of the modern dialects of Arabic. Fischer claims that the similarities among the modern dialects of Arabic can be traced back to this common origin (Fischer, 1995, p. 85-86). Ferguson lists 14 possible features of that koine which are discussed in detail elsewhere (al-Sharkawi, 2010, p. 106-109). A discussion of one of the suggested features as an elastration is in order here. It will show that it is difficult, given the state of data from pre-Islamic times, to ascribe any structural features to a particular process with any degree of certainty. The use of the dual is a good example.

Ferguson suggested that the development of the dual similarly in all the dialects of Arabic could not have come from the pre-Islamic situation, but must have come from a koine (Ferguson, 1959, p. 620). Two aspects of the dual in the dialects make it clear to Ferguson that this feature did not come about by means of a general drift. First, the dual morpheme was lost without a trace from verbs, adjectives, and pronouns. Should the development have come by means of drift, a residue of the dual must have remained in the system to point at the earlier phase. Second, dual nouns in the dialects require plural agreement in all the dialects, even when the referent is an inanimate or nonhuman noun. Ferguson claims that these two features are identical in all the modern dialects and are all different from Classical Arabic. This should tell them that the dual developed from a variety other than the Classical language. Here lies part of the problem.

The data they have seem to indicate that all morphological paradigms apart from nouns and verbs lost the dual distinction in pre-Islamic times, at least in the western parts of the Peninsula. The demonstrative pronoun in southern Yemen may have been invariable (Rabin, 1951, p. 72), the relative pronoun in Yemen was also invariable and did not respond to number or gender, and the same lack of response to gender and number affected the relative pronoun in Hudhayl as well (al-Sharkawi, 2010, p. 45). Although the fate of these 
paradigms in Hijaz is not clear, and or there is no reference to pronouns, it seems that the number and gender paradigms were in a state of development in pre-Islamic times. Combining this with the invariable treatment of the dual ending in Hijaz and Yemen and the development of the case system that they gave examples of above, one can see that the loss of the dual cannot be entirely ascribed to a koine (al-Sharkawi, 2010, p. 48). Ferguson ascribes such developments to the koine because he assumes that the language of pre-Islamic poetry was the vernacular of all the Arabs including those who took part in the conquests of Iraq, Syria and Egypt. This belief is controversial in itself.

Cohen modifies the idea of the koine even further. He suggests the existence of a post-conquest koine, but disputes the notion of a single unique koine in the conquered territories as a source of innovations. Socio-demographic circumstances of the conquests seem to support this reservation as migration to each garrison town must have been allowed only to those who belonged to the same tribes that took part in the early conquest. Cohen also asserts, and rightly so, that in order to use any structural feature as evidence for a koine, it has to be common to most if not all sedentary dialects, must not exist in the Bedouin or Classical varieties, and should not be attributable to drift. Many of the features of the koine Ferguson identified do not seem to fit, as they can be ascribed to various processes and/or varieties. Cohen proposes instead that there were many koines that originated in different areas and spread in different directions. In addition, the historical circumstances do not seem to support the idea of a single koine, although they support the idea of a koine. The spread of features of this koine from one place to another must have been difficult due to the lack of mass media and dissemination methods.

The available historical data show that Ferguson may have been correct in asserting the existence of a koineization process after the Arab conquests in the garrison towns. They do not agree with Ferguson, however, but instead agree with Cohen, that several koines must have existed, as the historical data show them that those who belonged to the tribes that first took part in the conquests inhabited different garrison towns. People who belonged to the eastern group of dialects built and inhabited Basra, while southeastern Hijazis inhabited Egypt. They know for a fact that these two groups differed on the case system and the dual. The leveling, regularization and simplification processes in each of these two general cases must have yielded, therefore, different koine results. How similar the structural output of the process is to modern dialects is beyond what the linguistic data can allow them to speculate.

The second linguistic strategy that resulted from the contact situation must have triggered which is the use of a form of a foreigner register by Arabs, the majority prestigious group, when communicating with non-Arabic speakers in garrison towns. The Arabs' desire to communicate with non-Arabs without a common third language, in the circumstances that imposed the choice of Arabic as a language of communication, must have convinced them to use simplification strategies. "Foreigner Talk" is a register that is universally used by the native speakers of any target language to communicate with non-native interlocutors for functional purposes. It is a group of structural modifications constructed in continua between the native speaker's unmodified speech and the most restructured utterance (al-Sharkawi, 2007, p. 116). It is an automatic process that is triggered as soon as the native speaker realizes that the interlocutor is not proficient enough in the target language. The degree of structural modification depends on the perceived level of proficiency of the non-native speaker (Gass, 1997, p. 66). This kind of structural modification happens in all languages of the world. It has been proven that Foreigner Talk registers are governed by some universal guidelines (Tweissi, 1990, p. 297). 
The most important structural feature of any "Foreigner Talk" register in Arabic, as they can glean from the scarce data on "Foreigner Talk" in modern dialects, is structural saliency. It is a trend that takes different shapes on all levels of linguistic analysis (al-Sharkawi, 2007, p. 116). On the phonological level, "Foreigner Talk" has slower speech rates than native speaker talk (Tweissi, 1990, p. 305), more primary stress on words than native speaker talk, more pauses than native speaker talk, less phonological processes than native speaker talk, and more short unstressed vowel insertions between morphemes than native speaker talk (al-Sharkawi, 2007, p. 116-117). The same trend of structural saliency characterizes "Foreigner Talk" morphology in Arabic. There is a tendency to avoid certain morphological features (the synthetic passive), redundancy, and use of analytical structures. Verb phrases, for example, mark the verb not only with affixes for person, gender, number, and aspect but also, in the beginning of each phrase, with a redundant nominal or pronominal head in addition to the affixes. In addition, there is a general preference for using genitive exponents for the construct case in the possessive structure, which renders the structure salient (al-Sharkawi, 2007, p. 113-114).

\section{Discussion}

Looking at Classical Arabic, Egyptian and urban dialects, especially Tunis Arabic, Bedouin dialects of Najd, and central Asian Arabic language islands, one can notice several phenomena as far as gender behavior is concerned. First, there is a formal morphological similarity in singular and plural gender morphemes among all these varieties. There is also a similar gender distribution on the singular forms of the various word classes. Gender distinction is present in the singular demonstratives, pronouns, nouns and verbs. These similarities indicate that all these varieties share the same proto-gender form. The common lack of gender representation in some paradigms shows that this proto gender form in Arabic was undergoing development before the Arabian diaspora in the seventh century and the emergence of the new urban vernaculars. Gender is not represented in the 1st person of the pronominal paradigm, independent and suffix. Nor is there gender in the first person verb conjugation in all tenses. Thus far, the common features between all the varieties of Arabic end. The second phenomenon that could be noticed is that the article divides the varieties of Arabic into two types, Classical Arabic in one type and the rest of the varieties in the other type.

Morphological development in the ancestor of Classical Arabic seems to have been thus far arrested. But the rest of the Arabic varieties seem to have developed further in the morphological representation of gender. All urban and Bedouin dialects lost gender representation on the relative pronouns as a category. In fact, relative pronouns lost their paradigmatic status all together, as they have not only lost gender distinction; they have also lost number distinction. It seems that this development happened before the seventh century as well, because it is common among all varieties of Arabic. There is no reflex of any older system that can indicate an older state for the relative pronoun. The third phenomenon that they can notice from the comparison indicates that the Bedouin dialects of the Arabian Peninsula, which did not migrate to the conquered lands, stopped development in gender morphologically and syntactically. Or, at least, they slowed this development. The dialects that developed in the conquered territories of the Middle East and North African have continued gender development both on the morphological and syntactic levels.

Morphologically, Bedouin dialects of Najd retained gender distinction on the plural independent and suffix pronouns in the second and third persons, on demonstratives, and on verbs of all tenses. Type three dialects lost gender distinction on the second and third persons plural on verbs and pronouns and on demonstratives as well, confining the morphological representation of gender to the singular number only. This split between the 
Bedouin type two dialects and the urban type three dialects must have taken place between the beginning of the Arab Diaspora in the mid seventh century and the beginning of the eighth century, since the central Asian varieties of Arabic, which did not go through the koineization and simplification processes of urbanization, retain the gender distinction on the plural of pronouns, demonstratives and verbs. The most reliable theory about the beginning of Arab tribal migration to central Asia seems to indicate to the late seventh early eighth centuries as the time point where these tribes left North Eastern Iraqi Arabia through Khurasan into Transoxania as an offshoot of the Arab invading army (Barfield, 1981, p. 3-4). If gender distinction in the plural was functional in the Arabic dialects in the 7th and 8th centuries, it must have been a part of the structural inventory of the varieties that formed the linguistic make-up of the garrison towns of Iraq, Egypt and North Africa, and must have been part of the structures that went through regularization, leveling, and borrowing processes of the suggested koineization process.

It is beyond the scope of this article to investigate the disappearance of the plural feminine syntactic agreement in the urban dialects. It was mentioned in the article quickly and in no great length in order to indicate that the difference between Najdi type two dialects and the Egyptian type three dialects went beyond paradigmatic morphological representation into a difference of the language type between languages that have a grammatical gender with morphological and syntactic representation and languages without gender distinction but with different word classes. Finally, the urban type three phenomena seem to be still in a process of developing its gender morphological paradigms. Some North African dialects have also lost gender distinction on the second person singular in pronouns and verbs. Although, this phenomenon seems to be confined to the urban dialects of Tunis, it is an indication as to how gender development could have taken place in the historical periods and how it would in the future if it would develop further.

\section{Conclusion}

They tried in this article to establish a correlation of a sort between an ecological and social process such as urbanization, and linguistic processes such as koineization and structural simplification. The purpose is to justify the split between two types of Arabic dialects; type two, Bedouin dialects, did not migrate to the new garrison towns that were established in the new Arab provinces in the seventh century and did not go through aforementioned linguistic processes. Type three urban dialects were formed in the new Arab provinces and in the newly established garrison towns. They went through these two processes and lost, among many differences from the Bedouin dialects, gender distinction on the plural and also syntactic gender agreement. The article did not claim that gender development did not start in pre-Islamic times. On the contrary, gender development seems to have been well under way before the Arab Diaspora. Common phenomena among all three types of dialects point to this direction. The main claim, however, is that processes of borrowing and leveling in the contact contexts of the new urban centers of garrison towns formed and proliferated gender indistinction in the plural.

\section{References}

Abboud-Haggar, S. (2006). Dialect Genesis. Encyclopedia of Arabic Language and Linguistics, vol. I, pp. 613-622. Ed. K. Versteegh, Leiden: Brill.

Al-Sayyad, N. (1991). Cities and Caliphs: On the Genisis of Arab Muslim Urbanism. New York, NY: Praeger.

all-Sharkawi, M. (2007). Foreigner Talk. Encyclopedia of Arabic Language and Linguistics vol. II, pp. 116-122. Ed. K. Versteegh, Leiden: Brill. 
al-Sharkawi, M. (2008). Pre-Islamic Arabic. The Encyclopedia of Arabic Language and Linguistics, vol. IV pp. 689-699. Ed. K. Versteegh, Leiden: Brill.

al-Sharkawi, M. (2010). The Ecology of Arabic: A Study of Arabicization. Leiden: Brill.

al-Sharkawi, M. (2013). The Development of the Dual Paradigm in Arabic. Al-'Arabiyya: Journal of the American Association of Teachers of Arabic, 43, 1-22.

al-Sharkawi, M. (2013). Urbanization and the Development of Arabic: The Case of Garrison Towns in the Seventh and Eighth Centuries CE, International Journal of Ancient History, 24, 60-70.

Aoun, J., Benmamoun, E. and Choueiri, L. ( 2010). The Syntax of Arabic. Cambridge: Cambridge University Press.

Auer, P. (2007). Mobility, Contact and Accommodation(Ed.). The Routledge Companion to Sociolinguistics (pp.109-115). C. Llamas, L. Mullany \& P. Stockwell. London: Routledge.

Bagnal, R. (1993). Egypt in Late Antiquity. Princeton: Princeton University Press.

Barfield, T. (1981). The Central Asian Arabs of Afghanistan. Austin: University of Texas Press.

Benmamoun, E. (2000). The Feature Structure of Functional Categories: A Comparative Study of Arabic Dialects. Oxford: Oxford University Press.

Blau, J. (1965). The Emergence of Middle Arabic(Ed.). The Emergence and Linguistic Background of Judeo-Arabic (pp.1-18). J. Blau. Oxford: Oxford University Press.

Brustad, K. (2000). The Syntax of Spoken Arabic: A Comparative study of Moroccan, Egyptian, Syrian, and Kuwaiti Dialects. Washington, DC: Georgetown University Press.

Cohen, D. (1962). Koine, Langues communes ou dialectes arabes. Arabica 9 (pp. 119-144).

Corbett, G. (1991). Gender. Cambridge: Cambridge University Press.

Corbett, G. (2007). Gender and Noun Classes (Ed.). Language Typology and Syntactic Description (vol. III, pp.241-279). T. Shopen. Cambridge: Cambridge University Press.

Corriente, F. (1976). From Old Arabic to Classical Arabic Through the Pre-Islamic Koine: Some Notes on the Native Grammarians' Sources, Attitudes, and Goals. Journal of Semitic Studies 21, 62-98.

Cowell, M. (1964). A Reference Grammar of Syrian Arabic. Washington, DC: Georgetown University Press.

De Jong, R. (2009). Sinai Arabic (Ed.). Encyclopedia of Arabic Language and Linguistics (vol. IV, pp.237-251). K. Versteegh, Leiden: Brill.

Fischer, W. (1961). Die Sprache der arabischen Sprachinsel in Uzbekistan. Der Islam 36, 232-263.

Gass, S. (1997). Input, Interaction and the Second Language Learner. New Jersey: Lawrence Earlbaum.

Gibson, M. (2009). Tunis Arabic (Ed.). Encyclopedia of Arabic Language and Linguistics (vol. IV, pp. 563-571). K. Versteegh, Leiden: Brill.

Hachimi, A. (2007). Gender (Ed.). Encyclopedia of Arabic Language and Linguistics (vol. II, pp. 155-164). K. Versteegh, Leiden: Brill.

Harrell, R. (1962). A Short Reference Grammar of Moroccan Arabic. Washington DC: Georgetown University Press.

Holes, C. (1990). Gulf Arabic. London: Routledge.

Holes, C. (2004). Modern Arabic: Structures, Functions, and varieties. Washington DC: Georgetown University Press.

Ingham, B. (1994). Najdi Arabic: Central Arabian. Amsterdam: John Benjamins.

Ingham, B. (2006). Afghanistan Arabic (Ed.). Encyclopedia of Arabic Language and Linguistics (vol. I, pp. 28-35). K. Versteegh, Leiden: Brill.

Ingham, B. (2008). Najdi Arabic (Ed.). Encyclopedia of Arabic language and Linguistics (vol. III, pp. 326-334). K. Versteegh, Leiden: Brill.

Ingham, B. (2009). Saudi Arabia (Ed.). Encyclopedia of Arabic Language and Linguistics (vol. IV, pp. 123-130). K. Versteegh, Leiden: Brill.

Janssens, G. (1972). Stress in Arabic and Word Structure in the Modern Arabic Dialects. Leuven: Peeters.

Johnstone, T. (1967). Eastern Arabian Dialect Studies. London: Oxford University Press.

Kusters, W. (2003). Linguistic Complexity: The Influence of Social Change on Verbal Inflection. Utrecht: LOT.

Labov, W. (2006). The Social Stratification of English in New York City, 2nd . Cambridge: Cambridge University Press.

Miller, C.(2004). Variation and Change in Arabic Urban Vernacular (Ed.). Approaches to Arabic Dialectology: A Collection of Articles Presented to Manfred Voidich on the Occasion of his Sixtieth Birthday (pp. 177-205). M. Haak, R. De Jong and K. Versteegh, Leiden: Brill.

Miller, C. et al. (2007). Arabic in the City: Issues in Dialect Contact and Language Variation. London: Routledge. 
Owens, J. (2000). Arabic as a Minority Language. Berlin: Mouton de Gruyter.

Prochazka, T. (1988). Saudi Arabian Dialects. London: Kegan Paul.

Rabin, H. (1951). Ancient West Arabian. London: Taylor's Foreign Press.

Thomason, S., \& Kaufman, T. (1988). Language Contact, Creolization and Genetic Linguistics. Berkeley: University of California Press.

Tuten, D. (2007). Koineization (Ed.). The Routledge Companion to Sociolinguistics (pp. 185-191). C. Llamas, L. Mullany \& P. Stockwell. London: Routledge.

Tweissi, A. (1990). Foreigner Talk: Evidence for the Universality of Language Simplification. Perspectives on Arabic Linguistics(pp. 296-320). Eds. M. Eid \& J. McCarthy. Amsterdam: John Benjamins.

Versteegh, C. (1984). Pidginization and Creolization: The Case of Arabic. Amsterdam: John Benjamins.

Versteegh, K. (1993). "Leveling in the Sudan: From Arabic Creole to Arabic dialects". International Journal of the Sociology of Language 99, 65-79.

Versteegh, K. (1997). The Arabic Language. New York: Colombia University Press.

Watson, J. (2007). The Phonology and Morphology of Arabic. Oxford: Oxford University Press.

Watson, J. (2009). Sanani Arabic (Ed.). Encyclopedia of Arabic Language and Linguistics (vol. IV, pp. 106-115). K. Versteegh, Leiden: Brill.

Zimmermann, G. (2009). Uzbekistan Arabic (Ed.).The Encyclopedia of Arabic Language and Linguistics (vol. IV, pp. 612-623). K. Versteegh, Leiden: Brill. 